\title{
UPAYA PENINGKATAN PRESTASI BERMAIN BOLA BASKET MENGGUNAKAN MODEL PEMBELAJARAN PROBLEM BASED LEARNING
}

\author{
Zaidin \\ SMP Negeri 1 Matan Hilir Selatan \\ Email: Zaidinsmpn1@gmail.com
}

\begin{abstract}
The development of sports in schools is really needed to improve the students' achievements of SMP Negeri 1 Matan Hilir Selatan, at its increased level. Seeing its success on basketball, it still needs very serious coaching to pursue the achievements. To achieve the desired performance certainly requires training, both technical trainings and tactics to strengthen the match team. For this, discipline, sportsmanship, the courage to work together and responsibilities are highly expected because in basketball games there are many rules that must be implemented, such as movements for throwing, catching, dribling, and shooting. There are several alternatives to come out with the method of playing like searching what problems of not understanding all movements Power (explosive power) and speed of reactivity, agility as well flexibility. In carrying out something work must have a purpose, so there is no deviation that can reach its goal as well in the implementation of this study. The authors have the purpose of knowing the relationship between speeding and dribling in the basketball skills by players. This research was conducted in Classroom Action Research Design.
\end{abstract}

$(C A R)$

Keywords: Achievement, Improvement, Efforts, Playing Basketball, Models

\section{PENDAHULUAN}

Perkembangan Olah raga disekolah sangat perlu peningkatan demi untuk memperoleh prestasi pada sekolah SMP Negeri 1 Matan Hilir Selatan, mengingat perkembangan olah raga di tingkat jenjangnya semakin meningkat. Dilihat dari keberhasilannya untuk cabang Bola basket ini masih perlu pembinaan yang sangat serius guna mencapai prestasi tersebut.

Untuk meencapai prestasi yang diinginkan tentu memelukan latihan, baik itu latihan tehnik atau taktik memperkuat team pertandingan. tentunya disiplin, sportivitas, berani bekerja sama dan tanggung jawabsangat diharapkan karena dalam permainan bola basket bayak peraturan yang harus di laksanakan, seperti gerakan lempar tangkap, mendrible, dan shoting.

Adapun permasalahan dan hambatan yang muncul dalam proses belajar- mengajar di SMP Negeri 1 Matan Hilir Selatan ini mempunyai banyak faktor-faktor yang berkaitan misalnya pemain itu sendiri, sarana dan prasarana yang ada, pelatih, latihan tehnik, dan taktik dalam bermain. Masalah pemain atau bibit olah ragawan cukup diminati oleg siswa/siswi, tinggal tergantung untuk memilih atlet yang baik. Tentunya kondisi fisik merupakan komponenkomponen yang tidak dapat dipisahkan untuk peningkatan hasil yang dicapai, seperti kekuatan, daya tahan, kecepatan, kelincahan dan keseimbangan.

Dalam usaha untuk mencapai prestasi yang maksimal, tentunya persiapan yang cukup panjang, bukan hanya ditekankan pada taktik maupun tehnik saja akan tetapi kondisi fisik atlet perlu penjagaan dan pengingkatan secara continyu dalam menghadapi latihan maupun pertandingan. Ada beberapa alternatif jalan keluar dengan metode bermain pada sekolah SMP Negeri 1 Matan Hilir Selatan seperti mencari masalah apa yang menjadi masalah yang tidak mengerti terhadap semua gerakan powor ( daya ledak ) dan Speed off 
reaktion ( kecepatan ) kelincahan maupun kelenturan. Tujuan penelitian ini untuk mengetahui hubungan antara kecepatan dengan keterampilan drible bola basket pada pemain baket dan untuk mengetahui hubungan antara kelenturan dengan keterampilan drible bola basket pada pemain basket.

\section{METODE PENILITIAN}

Jenis penelitian yang dilakukan dalam penelitian ini adalah Penelitian Tindakan Kelas (PTK). Penelitian tindakan kelas merupakan suatu pencermatan terhadap kegiatan belajar berupa sebuah tindakan, yang sengaja dimunculkan dan terjadi dalam sebuah kelas secara bersama. Tindakan tersebut diberikan oleh guru atau dengan arahan dari guru yang dilakukan oleh siswa. Subjek penelitian ini adalah siswa kelas VIII A SMP Negeri 1 Matan Hilir Selatan Tahun Pelajaran 2019 / 2020 dengan jumlah siswa 28 Orang pada semester ganjil. Sesuai dengan rancangan penelitian, penelitian tindakan ini dialaksanakan dalam dua siklus.

\section{HASIL PENELITIAN DAN PEMBAHASAN \\ Hasil \\ Siklus 1}

Tahap Perencanaan Tindakan. Dalam perencanaan pelaksanaan pembelajaran Peneliti Tindakan Kelas (PTK) ini, peneliti menggunakan rancangan kegiatan Berupa Rencana Pelaksanaan Pembelajaran yang di dalamnya mencakup skenario pembelajaran yang diimplementasikan dalam kegiatan belajar mengajar. Peneliti juga menggunakan seperangkat instrumen yang akan digunakan untuk pengumpulan data berupa lembar observasi kegitan guru dan tes formatif pada akhir pertemuan siklus 1, pendukung pembelajaran lainnya yaitu lembar kerja siswa (LKS), media dan alat peraga penggaris, Jangka ,Alat Tulis, Gunting, Kertas Asturo, Kertas Karton, Kardus, Lidi, dan Lem

Tahap Pelaksanaan Tindakan. Peneliti melaksanakan 2 kali pertemuan untuk siklus I. Sebelum guru menyampaikan tujuan pembelajaran, siswa diberikan motivasi bahwa belajar matematika itu tidak sulit, agar didalam hatinya tertanam rasa senang. Sebelum memulai materi siswa diberikan penjelasan tentang metode Penemuan terbimbing. Penerapan metode Penemuan terbimbing siswa mengerjakan LKS dan memperhatikan langkah-langkah kerjanya dengan menggunakan alat peraga yang sudah ada sehingga siswa dapat menemukan hasil dari pekerjaannya. Kemudian siswa menliskan jawabannya dilembar presentasi dengan waktu yang ditentukan, diharapkan masing-masing kelompok merasa semangat menampilkan hasil dari kelompok masingmasing. Kemudian pada siklus I pertemuan ke dua setelah presentasi kelompok selesai akan diberikan soal evaluasi individu (post test).

Pengamatan dilakukan observer mulai dari awal hingga akhir pembelajaran. Dengan fokus pengamatan terhadap tindakan yang diberika guru. Hasil pengamatan tertulis pada lembar observasi. Data hasil penelitian siklus 1 didapat dari merekap lembar observasi yang telah diisi oleh observer. Berikut ini ditampilkan data penelitian siklus 1 , dari masing-masing indikator yang tampak selama proses pengamatan.

Hasil analisis data pada table 4.3 dapat di ketahui bahwa secara umum penyampaian pembelajaran yang dilakukan oleh peneliti sudah baik, meskipun ada beberapan deskripsi yang belum dilakukan. Jika di hitung dengan rumus presentase dapat diketahu hasil observasi yang dilakukan peneliti adalah $77,14 \%$. hal tersebut sesuai dengan taraf keberhasilan tindakan yang berada pada skor pencapaian sebanyak 54, dari skor maksimal sebanyak 70 . Keberhasilan tindakan yang dilakaukan oleh peneliti berada pada kategori baik.

Beberapa hal yang perlu tingkatkan lagi dalam kegiatan pembelajaran yaitu: pada kegiatan awal, guru masih terasa tegang dalam membuka pembelajaran, guru belum benarbenar memotivasi siswa Pada kegiatan inti, terutama pada saat diskusi kelompok guru belum menguasai pengelolaan kelas karena ada beberapa siswa yang cuek/pasif. Guru hendaknya tidak terfokus pada salah satu kelompok saja. 
Berdasarkan pengamatan observer, dalam pelaksanaan kegiatan belajar mengajar pada siklus I masih terdapat kekurangan. Hal ini terlihat dengan adanya masalah-masalah yang muncul dan factor- faktor yang menyebabkannya. Oleh karena itu peneliti berupaya untuk mengadakan perbaikan yang akan dilaksanakan pada siklus selanjutnya. Upaya yang dilakukan peneliti diantaranya sebagai berikut:

a) Peneliti tidak lagi merasa tegang disaat pembelajaran

b) Peneliti berusaha untuk memotivasi siswa agar lebih percaya diri dalam menjawab ataupun bertanya jika ada suatu permasalahan

c) Peneliti harus menanamkan rasa percaya diri siswa terhadap kemampuannya

d) Peneliti perlu memperhatikan dan memberi pembinaan pada siswa agar mempunyai semangat untuk belajar sehingga hasil belajarnya bisa meningkat.

e) Peneliti harus berupaya memberikan penjelasan yang mudah dipahami dan mengarahkan siswa pada pemahaman metode Penemuan terbimbing yang baik pada materi.

Secara umum pada siklus I belum menunjukkan belum adanya peningkatan hasil belajar dan ketuntasan belajar masih belum memenuhi standar yang diharapkan, serta belum adanya keberhasilan pendidik dalam melaksanakan pembelajaran dengan metode Penemuan terbimbing. Oleh karena itu perlu dilanjutkan pada siklus II agar hasil belajar matematika siswa bisa ditungkatkan sesuai dengan yang diharapkan.

Tabel 1. Hasil Belajar Siswa Siklus I

\begin{tabular}{|c|c|c|c|c|}
\hline No & Nama Siswa & $\begin{array}{c}\text { Jenis } \\
\text { Kelamin }\end{array}$ & $\begin{array}{l}\text { Total } \\
\text { Nilai }\end{array}$ & $\begin{array}{c}\text { Ketuntasan Belajar } \\
(\mathrm{T} / \mathrm{TT})\end{array}$ \\
\hline 1 & Ade ahmad & $\mathrm{L}$ & 72 & Tuntas \\
\hline 2 & Ale andri & $\mathrm{L}$ & 59 & Tidak Tuntas \\
\hline 3 & Ali akbar & $\mathrm{L}$ & 50 & Tidak Tuntas \\
\hline 4 & Dewi anjuni & $\mathrm{L}$ & 62 & Tidak Tuntas \\
\hline 5 & Dilla puspita & $\mathrm{L}$ & 70 & Tuntas \\
\hline 6 & Iing anugrah & $\mathrm{L}$ & 72 & Tuntas \\
\hline 7 & Jeki perwadi & $\mathrm{P}$ & 76 & Tuntas \\
\hline 8 & Lisa rara santya & $\mathrm{L}$ & 52 & Tidak Tuntas \\
\hline 9 & Lisda yanti & $\mathrm{P}$ & 59 & Tidakn Tuntas \\
\hline 10 & Andriansyah & $\mathrm{L}$ & 56 & Tidak Tuntas \\
\hline 11 & M. Khalid Abdullah & $\mathrm{L}$ & 70 & Tuntas \\
\hline 12 & Pajarudin & $\mathrm{L}$ & 60 & Tidak Tuntas \\
\hline 13 & Rianto & $\mathrm{L}$ & 72 & Tuntas \\
\hline 14 & Ririn ariani & $\mathrm{P}$ & 39 & Tidak Tuntas \\
\hline 15 & Riviva & $\mathrm{P}$ & 72 & Tuntas \\
\hline 16 & Safityri & $\mathrm{P}$ & 72 & Tuntas \\
\hline 17 & Selfi & $\mathrm{L}$ & 51 & Tidak Tuntas \\
\hline 18 & Sintya komalasari & $\mathrm{L}$ & 46 & Tidak Tuntas \\
\hline 19 & Siti jumilah & $\mathrm{P}$ & 73 & Tuntas \\
\hline
\end{tabular}




\begin{tabular}{lcllc}
\hline 20 & Suci inriana & P & 72 & Tuntas \\
\hline 21 & Thony chan & L & 55 & Tidak Tuntas \\
\hline 22 & Tiara purmanasari & $\mathrm{P}$ & 56 & Tidak Tuntas \\
\hline 23 & Tri pebriansyah & $\mathrm{P}$ & 73 & Tuntas \\
\hline
\end{tabular}

\section{Siklus II}

Berdasarkan hasil pengamatan dan tindakan yang telah dilaksanakan oleh peneliti pada peneliti pada siklus pertama, menunjukkan bahwa tingkat pemahaman dan hasil belajar siswa terhadap materi garis singgung lingkaran masih belum begitu optimal. Oleh sebab itu untuk meningkatkan hasil belajar siswa, peneliti sebaik mungkin menerapkan metode Penemuan terbimbing di dalam pembelajaran.

Dari hasil refleksi observer menginformasikan agar lebih baik lagi dalam proses pembelajaran terutama pada bagian pembelajaran yang kurang terlaksana dengan baik, sehingga hasil yang diharapkan tercapai. Pada pelaksanaan ini dilakukan pada hari senin tanggal 7 Okteber 2019 dalam satu kali pertemuan. Proses pembelajaran pada siklus II ini hampir sama dengan tahapan siklus I, tidak ada perubahan dalam kelompok siswa, hanya saja ada beberapa perubahan yakni perbaikanperbaikan, agar dalam pelaksanaan dalam siklus II nanti dapat lebih optimal.

Guru bersama siswa melakukan pembelajaran sesuai dengan skenario tindakan yang tertulis dalam RPP. Sebelum guru menyampaikan tujuan pembelajaran, siswa diberikan motivasi dengan memberikan semangat dan membuat suasana belajar lebih rileks, dan pada saat guru mengorganisasikan siswa dalam kelompok diberikan waktu yang ditentukan bersama sehingga mereka bersemangat untuk bekerja sama dalam kelompoknya. agar didalam hatinya tertanam rasa senang. siswa diminta mengerjakan LKS dan melaksanakan kerja kelompoknya dengann pengawasan guru atau bimbingan guru dari LKS beserta langkah-langkan kerjanya dan alat peraga askali siswa menemukan apa yang mereka lakukan dan mencatat hasilnya, kemudian masing-masing kelompok mempresentasikan hasil kelompoknya didepan kelas. Kemudian elompok lain membandingkan hasil pekerjaanya.. Kemudian pada siklus I pertemuan ke dua setelah materi yang diajarkan selesai dan presentasi kelompok selesai akan diberikan soal evaluasi individu (post test). Pengamatan dilakukan oleh observer mulai dari awal hingga akhir pembelajaran. Dengan fokus pengamaan terhadap perkembangan tindakan tang diberukan peneliti atau guru. Pengamatan dilakukan dengan mengisi lembar observasi yang telah disiapkan oleh peneliti.

\section{Pembahasan}

Setelah kegiatan penelitian yang dilaksanakan dari tanggal 16, 18 September 2018 samapi dengan 7, 9 Okteber 2018 dikelas VIII A SMP Negeri 1 Matan Hilir Saltan peneliti menganalisis data hasil belajar dan hasil observasi selama proses belajar berlangsung sebagai berikut. Berdasarkan hasil yang diperoleh pada kegiatan siklus I, dari 28 orang siswa hanya 8 siswa (42\%) saja yang berhasil memperoleh nilai tuntas yaitu $>70$, sedangkan 11 orang siswa $(58 \%)$ belum memenuhi nilai ketuntasan dengan rata-rata 60,73 .

Hal ini dapat dilihat pada hasil tes hasil belajar tabel 1. nilai tertinggi adalah 76 sedangkan nilai terendah adalah 39 dengan rata-tata 75,04 . Rendahnya hasil yang diperoleh pada siklus I ini disebabkan karena siswa masih bingung kegiatan menemukan garis singgung dari melukis lingkaran. Dalam mengerjasakan soal tes siswa masih belum teliti dalam mengerjakan soal. Pada kegiatan gurunya juga ditemui beberapa hal yang kurang dalam pembelajaran. Yaitu pemanfaatan waktu yang kurang efisien, kurang mempersiapkan kelas untuk belajar, guru kurang memberikan penguatan berupa motivasi kepada siswa yang kurang aktif. Kemudian kegiatan perbaikan dilanjutkan dengan siklus ke 2. Pada siklus 2 ini hasil 
yang didapat menunjukkan adanya peningkatan yang memuaskan. Tingkat ketuntasan yang dicapai oleh siswa mengalami peningkatan yaitu dari $42 \%$ menjadi 79\%. Bearti dari 19 orang siswa 15 orang siswa telah berhasil mencapai nilai $\geq$ 70. Nilai yang diperoleh siswa diharapkan pada siklus 1 mereka masih bingung dengan cara kerja yang tercantum dalm LKS untuk menemukan garis singgung lingkaran sehingga siswa masih banyak bertanya, bahkan beberapa diantara mereka masih ada yang cuek/ pasif. Setelah dilaksakan perbaikan pembelajaran pada siklus 2 diperoleh hasil bahsa siswa lebih aktif dari siklus 1 . Mereka sudah tau apa yang mereka lakukan untuk menyelesaikan soal-soal bahkan mereka sudah bisa membagi tugas kelompoknya. Hal ini disebabkan mereka sudah mempunyai pengalaman saat proses pembelajaran di siklus 1 .

Berdasarkan observasi yang telah dilakukan, aktivitas peneliti mengalami peningkatan dari siklus I ke siklus II, peningkatan tersebut dapat dilihat pada tabel berikut:

Berdasarkan hasil pengamatan pada kegiatan guru, diperoleh data bahwa pada silus 1 diketahui beberapa kekurangan mempersiapkan kelas untuk belajar, guru kurang memberi penguatan berupa motivasi kepada siswa yang kurang aktif dalam pembelajaran, dan kurang memberikan pujian kepada siswa yang aktif. Guru belum optimal membimbing siswa. Setelah diadakan perbaikan pembelajaran di siklus 2 kegiatan guru sudah mengalami peningkatan kearah yang baik dimana hal-hal yang kurang dalam siklus 1 sudah dilaksankan disiklus 2, yaitu sudah lebih baik dalam penggunaan waktu, sudah lebih baik dalam mempersiapkan kelas untuk kegiatan belajar, sudah memberikan motivasi kepada siswa dalam kegiatan pembelajaran.

\section{SIMPULAN DAN SARAN Simpulan}

Berdasarkan uraian dan analisis penelitian yang telah dilakukan, maka dapat diambil kesimpulan sebagai berikut: (1) Pada siklus 1 siswa tidak begitu aktif dalam kegiatan pembelajaran. Hal ini disebabkan karena mereka belum mengetahui degan cara kerja yang tercantum dalam buku siswa kelas VIII untuk menemukan beberapa masalah tentang permainan bola basket bahkan beberapa diantara mereka masih ada yang kurang mengemari. Gurupun menyadari akan kekurangan ini. Maka pada siklus 2 guru merancang pembelajaran dan buku siswa Kelas VIII yang lebih mudah dipahami siswa.dengan demikian siswa dapat bermain bola basket sesuai dengan tujuan pembelajaran. (2) Presentase pencapaian tingkat ketuntasan siswa paa siklus 1 masih jauh dari yang diharapkan, pada siklus 1 ini presentase ketuntasan hasil belajar baru mencapai $42 \%$ (8 orang) dari jumlah siswa 28 orang. Setelah dilakukan perbaikan pembelajaran pada siklus 2 presentase ketuntasan mengalami peningkatan hasil belajar menjadi $79 \%$ (28 orang). Maka kemampuan belajar dan prestasi siswa akan tercapai.

\section{Saran}

Pembelajaran dengan metode Problem Based Learning dapat dijadikan sebagai salah satu alternatif dalam pengajaran di sekolah agar program pengajaran penjaskes di sekolah menjadi lebih berkembang.

\section{DAFTAR PUSTAKA}

Aip Syariffudin, 1997, Pendidikan Jasmani Dan Kesehatan. Jakarta PT . Gramedia Widiasarna Indonesia.

Engkos Kosasih, 1985, Olah Raga Teknik Program Latihan, Jakarta, AkademiPres.

Harsono, 1988, Coaching dan Aspek-Aspek Psikologi Dalam Coaching, Jakarta, Proyek Pengembangan Lembaga Pendidikan Tenaga Kependidikan.

Iskandar ZA. dan Engkos Kosasih 1986, Pelatihan Peregangan. Jakarta Akademika Pers.

M Sajoto 1985, Peningkatan Dan Pembinaan Kekuatan Kondisi Fisik Dalam Olahraga. Semarang.

Nur Hasan, 1986, Tes Dan Pengukuran 
Jakarta, Karunia Universitas Terbuka. Suharsimi arikunto, 1987, Dasar-Dasar Evaluasi Pendidikan Jakarta, Bina Aksara. Suharsimi Arikunto, 1991, Prosedur Penelitian Sesuatu Pendekatan. Praktis, Jakarta PT. Rineka Cipta.
Sutrisnop Hadi, 1987, Statistic II Yogyakarta Yayasan Penerbit Fakultas Psikologi UGM.

Sutrisno Hadi, 1990, Analisis Egresi Yogyakarta Andi Offse 